\title{
Esbozo de análisis epistemológico de las investigaciones de Eugenia del Pino sobre el desarrollo animal
}

\section{Outline of an epistemological analysis concerning the investigations of Eugenia del Pino about animal development}

\author{
OSWALDO BÁEZ TOBAR \\ Universidad Central del Ecuador, Ciudadela Universitaria Av Améríca, Quito - Ecuador \\ oswaldobaez@hotmail.com
}

\section{RESUMEN}

El presente estudio contiene una síntesis de las investigaciones del desarrolloembrionario de las ranas marsupiales, realizadas porlabióloga ecuatoriana Eugenia del Pino y sus colaboradores en el Laboratorio de Biología del Desarrollo de la Pontificia Universidad Católica del Ecuador en Quito, con la colaboración de investigadores extranjeros. Resume el aporte original de la Dra. del Pino al conocimiento de la biología del desarrollo de las ranas marsupiales, logrado mediante el trabajo sistemático y bien orientado de más de cuatro décadas; por lo que es pertinente y necesario hacer un análisis epistemológico de sus investigaciones realizadas para revelar el proceso de construcción del conocimiento científico sobre la biología de la rana marsupial, Gastrotheca riobambae y otras especies comparándolo con Xenopus laevis. Eugenia del Pino descubrió las características de desarrollo embriónico y buscó explicaciones causales, formuló hipótesis y diseñó experimentos para constatar los hechos y fenómenos y estructuró una explicación teórica; todo esto en una magnífica concatenación de las causas y sus efectos, en una línea investigativa consistente y bien sustentada. El presente análisis ha sido posible hacerlo partiendo de una revisión exhaustiva de las publicaciones de Eugenia del Pino, que tuvo la oportunidad de completar su formación como bióloga e investigadora en universidades de Estados Unidos de América y Europa. Sus aportes tienen alta significación para el desarrollo de la biología experimental en el Ecuador y han sido reconocidos por la comunidad científica nacional e internacional. Este análisis comprende los siguientes aspectos: Inicios de la investigación y esbozo de análisis epistemológico. Se explican las adaptaciones reproductivas de la rana marsupial $G$. riobambae que incluye los modos de oogénesis, la bolsa materna y su control hormonal. Se explica la preparación de la bolsa materna para la incubación de los embriones y la relación entre los embriones y la bolsa materna. Se señala que la incubación embriónica está acompañada de adaptaciones de la función excretora, cambios en el ritmo del desarrollo embrionario temprano y cambios en el 
proceso de la gastrulación, con la formación de un disco embriónico. Las ranas marsupiales tienen retardo en el alargamiento del cuerpo. Se explican las líneas recientes de trabajo. Las conclusiones resaltan la trascendencia de sus investigaciones.

Palabras clave: ranas marsupiales, biología del desarrollo, análisis epistemológico.

\section{ABSTRACT}

This work summarizes the studies about the embryonic development of marsupial frogs that were performed by Eugenia del Pino, an Ecuadorian Biologist, and her collaborators at the Laboratory of Developmental Biology of the Pontifical Catholic University of Ecuador in Quito, with the collaboration of foreign scientists. This analysis summarizes the original contribution of Dr. del Pino to the knowledge of the Developmental Biology of marsupial frogs. Her results were achieved by systematic and well oriented work conducted for more than four decades. For this reason, an epistemological analysis of her research is pertinent and necessary in order to reveal the knowledge construction process in the study of the marsupial frog Gastrotheca riobambae and other frogs in comparison with Xenopus laevis. Eugenia del Pino discovered the features of embryonic development and searched for causal explations. She formulated hypothesis and planned experiments to identify the facts and phenomena in order to formulate a theoretical explanation. All of this was done within a consistent and well supported research line. The present analysis was possible through an exhaustive revision of the publications of Eugenia del Pino, who completed her training as biologist and investigator in universities of the United States of
America and Europe. Her contributions have high significance for the development of experimental biology in Ecuador, and have been recognized by the national and international scientific communities. This analysis includes the following themes: Onset of research and outline of the epistemological analysis. The revision includes the reproductive adaptations of the marsupial frog $G$. riobambae, the modes of oogenesis, and the maternal pouch and its hormonal control. The changes in the maternal pouch for embryonic incubation and the relationship between the embryos and the maternal pouch are reviewed. The embryonic incubation is accompanied by adaptations of the excretory function, changes in the rate of early embryonic development and changes in the process of gastrulation with the formation of an embryonic disk. Body elongation is retarded in marsupial frogs. The current research lines are described. The conclusions highlight the significance of her research.

Key words: marsupial frogs, developmental biology, epistemological analysis.

\section{INTRODUCCIÓN}

Las investigaciones sobre la biología del desarrollo de las ranas marsupiales se iniciaron en el Ecuador con los primeros trabajos que en este campo realizó Eugenia del Pino en la Escuela de Ciencias Biológicas de la Pontificia Universidad Católica del Ecuador, PUCE, Quito en 1973, que han continuado pormás de 40 años. Eugenia M. del Pino es Licenciada en Ciencias de la Educación con la Especialización de Biología por la PUCE, en Quito; Magister en Ciencias por Vassar College, Poughkeepsie, New York, Doctora (Ph D) por Emory University, Atlanta, Georgia y Visitante del Instituto Carnegie para la 
Ciencia, Laboratorio de Embriología, Baltimore, Maryland, Estados Unidos de América. Es preciso destacar que las becas otorgadas por el Programa de Becas para América Latin (LASPAU) en 1967 y de la Comisión Fulbright Ecuador en 1990 para realizar sus estudios e investigaciones en los Estados Unidos tuvieron una importancia determinante en su preparación científica y entrenamiento en la investigación biológica; a ello se debe la solidez de su formación como científica y el inicio de su carrera como investigadora que le llevó a alcanzar reconocimiento e importantes distinciones de la comunidad científica nacional e internacional.

A su retorno al país en 1972, Eugenia del Pino se integró a la Escuela de Ciencias Biológicas de la PUCE como profesora-investigadora; planeaba continuar sus investigaciones sobre la biología del desarrollo de la rana acuática africana Xenopus laevis (Pipidae), que es la especie modelo de laboratorio para el estudio de la biología del desarrollo de los anfibios; pero ante la dificultad para traer ejemplares de esta especie, buscó una especie ecuatoriana de fácil obtención y la encontró en los jardines de la PUCE: la rana marsupial Gastrotheca riobambae (Hemiphractidae). Así empezó a estudiar la reproducción y la embriología de la rana G. riobambae, en ella encontró importantes diferencias respecto a $X$. laevis, lo que constituyó una novedad en el ámbito científico nacional e internacional. De esta forma abrió una línea de investigación para esclarecer los aspectos celulares y moleculares del desarrollo de varias especies de ranas del Ecuador. En este ámbito se inscriben más de 80 trabajos científicos publicados en revistas científicas de todo el mundo, entre ellas: Nature, Development y Scientific American; así como numerosas presentaciones en cursos, congresos y conferencias en universidades del país y del exterior.
Las investigaciones de Eugenia del Pino se orientaron al estudio de la reproducción, oogénesis y desarrollo embrionario de las ranas, en particular de la rana marsupial G. riobambae. Sus logros reflejan la continuidad de su quehacer científico, el análisis profundo de los temas de investigación dirigidos a la biología del desarrollo de los anfibios anuros, lo que tiene alto valor comparativo con otras especies, pues ha revelado diferencias en aspectos morfológicos, citológicos y moleculares, que han sido publicados en artículos científicos y en libros especializados de los cuales es autora y coautora.

Eugenia del Pino destaca que sus investigaciones se vieron favorecidas porque cuando inició sus estudios, el desarrollo embrionario de la rana marsupial Gastrotheca riobambae y de otras ranas con adaptaciones terrestres de reproducción eran temas totalmente nuevos para la ciencia: al descubrir que los embriones son incubados dentro del cuerpo de la madre de G. riobambae encontró que el desarrollo embrionario de la rana marsupial es mucho más lento que el de la rana Xenopus laevis, lo cual ha favorecido el espaciamiento en el tiempo de aspectos relacionados con el control molecular. En tanto que los varios procesos del desarrollo se solapan durante el rápido desarrollo de los embriones de X. laevis, por lo cual no es posible diferenciar la identidad independiente de dichos procesos. Los estudios comparativos con $G$. riobambae ayudan a comprender la identidad de los procesos del desarrollo embrionario.

En el laboratorio de Biología del Desarrollo de la PUCE se estudiaron las características de la oogénesis y desarrollo embrionario de varias especies de ranas de la familia Hemiphractidae, que incluye a las ranas marsupiales, particularmente Gastrotheca riobambae y Flectonotus pygmaeus; aspectos del desarrollo temprano de varias especies de 
las ranas dendrobátidas, en particular de la especie Epipedobates machalilla; dos especies de las ranas con nidos de espuma del género Engystomops (Leptodactylidae) y dos especies de las ranas de cristal de los géneros Espadarana y Hyalinobatrachium (Centrolenidae). El mencionado laboratorio se posicionó como uno de los centros de investigación biológica del Ecuador más reconocido en el ámbito científico internacional, particularmente por las contribuciones al conocimiento de la biología del desarrollo de anfibios anuros.

\section{EL DESARROLLO DE LAS RANAS MARSUPIALES}

\section{Esbozo de análisis epistemológico}

Eugenia del Pino encontró en la rana Gastrotheca riobambae un excelente modelo para continuar sus investigaciones sobre el desarrollo embrionario temprano, pues además de ser frecuente en Ecuador, no se conocía nada sobre su embriogénesis, por lo que decidió iniciar esa línea de investigación sustentada de sus conocimientos científicos y la metodología que había adquirido en su época de estudios.

Partió del conocimiento de que el desarrollo de las ranas de la familia Hemiphractidae tiene lugar en el cuerpo de la hembra mediante un proceso de incubación en la espalda materna al cabo del cual nacen ranitas plenamente formadas y en algunas especies renacuajos avanzados que son liberados en el agua, pero más aún $G$. riobambae y Flectonotus pygmaeus (una rana marsupial venezolana) así como otras especies de Hemiphractidae poseen una bolsa materna para la incubación de los huevos y los embriones, característica por la cual se las conoce como ranas marsupiales. Estas características son excepcionales en los anfibios por lo que suscitaron varias interrogantes que la investigadora fue resolviendo en el curso sus investigaciones; por lo mismo resulta pertinente y necesario iniciar un análisis epistemológico con el propósito de identificar temas esenciales del proceso de investigación llevado a cabo en forma sostenida en el tiempo.

La presente aproximación epistemológica, que se realiza a través del hilo conductor de las investigaciones y sus resultados, busca encontrar la coherencia lógica, amplitud y fundamentación del contenido sobre los conocimientos fundamentales del desarrollo embriónico temprano de los animales en general y en particular de la biología del desarrollo de los anfibios anuros, el encadenamiento causal y el alcance explicativo; atributos que encontró en el curso de las investigaciones sobre el desarrollo de las ranas marsupiales y cuyos hitos principales se exponen a continuación. La revisión integral de las investigaciones de Eugenia del Pino constituye un aporte significativo al conocimiento científico e ilustra en forma nítida una metodología de investigaciones experimentales, que son un ejemplo para los jóvenes investigadores como se aprecia en la secuencia de los procesos investigativos que constan a continuación.

\section{Adaptaciones reproductivas de Gastrotheca riobambae}

Eugenia del Pino encontró que las principales adaptaciones de la rana marsupial Gastrotheca riobambae se relacionan con la oogénesis, las adaptaciones materno-embriónicas para la incubación de los embriones en la bolsa materna, la velocidad del desarrollo embrionario y el tamaño y número de huevos. Los huevos de G. riobambae miden $3 \mathrm{~mm}$ de diámetro, son más grandes que los huevos de Xenopus laevis 
de 1,2 mm de diámetro, pero más pequeños que los de otras especies de la familia Hemiphractidae cuyos huevos pueden alcanzar $10 \mathrm{~mm}$ de diámetro. La rana, G. riobambae, produce e incuba un promedio de 87 huevos en cada estación reproductiva; la estación reproductiva dura aproximadamente 4 meses, al cabo de los cuales emergen de la bolsa materna renacuajos de 2 centímetros de longitud que son depositados por la madre en charcas permanentes o temporales donde crecen, realizan la metamorfosis y adquieren la forma de ranitas; el período acuático dura de tres meses a un año, según las condiciones ambientales.

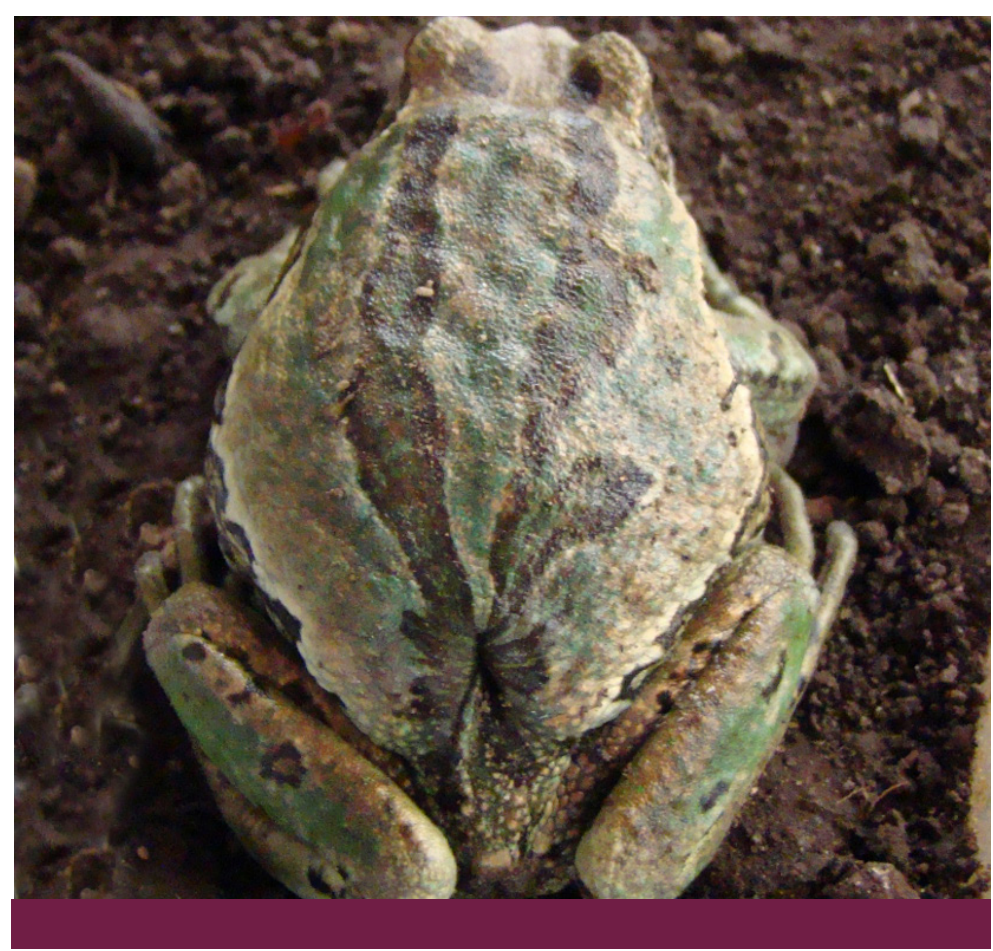

Hembra de la rana Gastrotheca riobambae con embriones en su bolsa dorsal. Foto: Eugenia del Pino

\section{La oogénesis multinucleada y mononucleada}

La oogénesis es el proceso de formación del oocito en el ovario, que después de experimentar un proceso de crecimiento y maduración meiótica, se convierte en óvulo. En las diferentes especies de sapos y ranas la oogénesis tiene particularidades específicas, por lo que la investigadora trató de determinar cómo es la oogénesis en su especie modelo: la rana marsupial Gastrotheca riobambae. Como en la rana Xenopus laevis y en la mayoría de vertebrados, los oocitos de $G$. riobambae contienen un único núcleo, denominado vesícula germinal, durante todo el período de la oogénesis. Por el contrario, E. del Pino encontró que en la rana marsupial Flectonotus pygmaeus los oocitos tempranos contenían numerosos núcleos o vesículas germinales. El número de núcleos se redujo a uno solo al culminar el período de la oogénesis, de modo que el gameto femenino tenía un único núcleo haploide una vez que se completó la meiosis.

Eugenia del Pino y A. Alan Humphries Jr. denominaron oogénesis multinucleada al modo de oogénesis con numerosos núcleos como en Flectonotus pygmaeus y oogénesis mononucleada al modo de oogénesis con un único núcleo, como en Xenopus laevis y Gastrotheca riobambae. Se determinó la oogénesis en 33 especies de Hemiphractidae: la oogénesis de 12 especies era multinucleada y en 21 especies, los oocitos fueron mononucleados. Los detalles de las características de la oogénesis multinucleada se estudiaron principalmente en Flectonotus pygmaeus y la oogénesis mononucleada en Gastrotheca riobambae, llegando a determinar en cada caso las particularidades de los procesos oogenéticos que revelan dos modos diferentes para la formación de los oocitos.

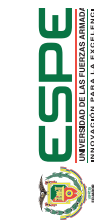


Los numerosos núcleos de los oocitos de F. pygmaeus tienen las características de núcleos meióticos rodeados por la membrana nuclear. Los núcleos múltiples son activos en la síntesis de RNA, tienen cromosomas plumosos y numerosos nucléolos. Además, cada núcleo presenta un nivel bajo y variable de la amplificación extracromosomal de los genes ribosomales mayores (de 18S, $28 \mathrm{~S}$ y $5.8 \mathrm{~S}$ ) en comparación con los oocitos de Xenopus laevis. Si se toma en cuenta a todos los 2.000 o más núcleos celulares de un oocito de $F$. pygmaeus, el nivel de amplificación de los genes ribosomales supera grandemente al de los oocitos mononucleados de X. laevis. La amplificación de los genes ribosomales durante la oogénesis facilita la formación de ribosomas, necesarios para la síntesis proteica que el embrión realizará a futuro.

En conclusión los dos modos de oogénesis, son dos opciones que toman las especies para preparar sus óvulos y cumplir su función reproductiva, o dos formas alternativas de cómo el núcleo o los núcleos de los oocitos multinucleados proveen los productos génicos que se requieren para sustentar el desarrollo embrionario temprano. La oogénesis multinucleada está en relación con la mayor rapidez del proceso oogenético, lo que se comprueba en Flectonotus pygmaeus. En cambio en G. riobambae, que realiza oogénesis mononucleada, el proceso de oogénesis es menos acelerado, sin embargo en las dos especies el desarrollo embrionario ocurre a un ritmo lento si se compara con Xenopus laevis.
El estudio de la oogénesis multinucleada se dificulta debido a que las especies que presentan este modo de oogénesis son muy

\section{Oogénesis mononucleada en Gastrotheca riobambae}

difíciles de encontrar en la naturaleza. Por tal motivo, Eugenia del Pino se concentró en el análisis de los oocitos mononucleados de Gastrotheca riobambae para determinar similitudes y diferencias con los oocitos multinucleados de Flectonotus pygmaeus y con los oocitos mononucleados de Xenopus laevis.

El genoma de X. laevis, contiene aproximadamente 400 copias del gen de 5S RNA ribosomal (rRNA) de tipo somático y 24.000 copias del gene de tipo oocito. Estos genes se expresan exclusivamente en las células somáticas del cuerpo o en los oocitos, respectivamente. Cabe señalar que para el ensamblaje de los ribosomas se requiere una copia de cada uno de los rRNA mayores de $28 \mathrm{~S}, 18 \mathrm{~S}$ y $5.8 \mathrm{~S}$ y una copia del rRNA de 5S. Para la acumulación de inmensas cantidades de ribosomas durante la oogénesis de $X$. laevis hay dos estrategias diferentes. En primer lugar, la amplificación extra-cromosomal de los genes ribosomales mayores provee numerosas copias de estos genes que sirven de base para la síntesis de los rRNA de 28S, $18 \mathrm{~S}$ y $5.8 \mathrm{~S}$, y en segundo lugar la presencia de un inmenso número de copias múltiples de los genes tipo oocito en el genoma haploide permite la síntesis de muchísimas copias de los $5 \mathrm{~S}$ rRNA. De esta manera se asegura las cantidades equivalentes de los varios tipos de rRNA que permitirán el ensamblaje del gran número de ribosomas durante la oogénesis. La magnitud de esta estrategia molecular se revela en el hecho de que los ribosomas que se sintetizan durante la oogénesis abastecen la síntesis proteica de los embriones hasta alcanzar el estadío de renacuajo temprano. La acumulación de ribosomas durante la oogénesis es una estrategia molecular que acelera el desarrollo embrionario de $X$. laevis, porque las células embrionarias pueden acelerar sus procesos de síntesis proteica debido a que no requieren primeramente sintetizar los rRNA para ensamblar sus ribosomas. 
Debido al interés comparativo, E. del Pino secuenció y analizó los genes ribosomales de $5 S$ rRNA de G. riobambae. Se encontraron 500 copias de una sola especie de genes de 5S rRNA en el genoma haploide, similar al gen de tipo somático de X. laevis. En el genoma de $G$. riobambae, no se detectaron genes de 5 S rRNA de tipo oocito. Es posible que los genes de tipo oocito se encuentren repetidos en números bajos, por lo que no fue posible detectarlos. Estos resultados se asemejan a la situación del ratón, organismo en cuyo genoma haploide se ha reportado ausencia de genes tipo oocito y 400 copias del gene de tipo somático.

La oogénesis de G. riobambae es síncrona, lo que significa que un solo grupo de oocitos alcanza su tamaño final en cada estación reproductiva. Esto está asociado con la incubación de los embriones en la bolsa materna, pues durante la incubación embrionaria los oocitos del ovario no crecen o lo hacen lentamente, pero después del nacimiento de los renacuajos, un nuevo grupo de oocitos crece en preparación para el siguiente proceso reproductivo; lo que tendría similitud con los mamíferos. En cambio en el ovario de X. laevis, se encuentran oocitos de todos los tamaños en el ovario, una estrategia que debe permitir el desove tan pronto se tengan las condiciones ambientales apropiadas.

Eugenia del Pino encontró que los oocitos de G. riobambae son mononucleados durante toda la oogénesis. En su único núcleo o vesícula germinal se observan cromosomas plumosos, nucléolos y otros orgánulos y proteínas nucleares con similitud a las presentes en los oocitos de X. laevis. La diferencia más significativa es el tamaño final del oocito, que es mayor en $G$. riobambae, con $3 \mathrm{~mm}$ de diámetro en comparación con 1,2 mm de diámetro en Xenopus laevis.

\section{La formación de la bolsa materna en las ranas marsupiales}

Debido a que los embriones de las ranas de la familia Hemiphractidae se desarrollan en la espalda materna, E. del Pino encontró modificaciones en la morfología y fisiología de la madre, así como cambios importantes en los embriones. En efecto, en las especies más especializadas como Flectonotus y Gastrotheca la bolsa materna llega a ser una estructura permanente de las hembras. La bolsa materna se abre en la parte posterior del dorso, por encima de la cloaca en Gastrotheca riobambae. La bolsa materna es una formación derivada de la piel: similar a un plegamiento de la piel dorsal con una estructura histológica comparable a la piel de hembra adulta de $G$. riobambae cuando no aloja embriones. Sin embargo, la bolsa materna carece de glándulas de veneno pero conserva glándulas mucosas. Una estructura similar se ha observado en otras especies del género Gastrotheca que incuban hasta el estadio de renacuajos como hasta ranas juveniles.

Uno de los hechos más interesantes constituye el cambio histológico de la bolsa marsupial durante la incubación embrionaria. La bolsa de G. riobambae se agranda, ocupa el dorso y las partes laterales de la espalda de la hembra, las paredes se adelgazan y vascularizan, forman compartimientos individuales para cada uno de los aproximadamente 87 embriones que una hembra incuba en promedio. Una vez expulsados los renacuajos, la bolsa adquiere características similares a la piel de la rana. La abertura de la bolsa materna de G. riobambae mantiene los bordes separados, es decir está abierta cuando los ovarios son pequeños y la hembra no está en la fase de reproducción; en cambio cuando la hembra tiene los ovarios crecidos, la bolsa se cierra al igual que durante la incubación de los embriones, para abrirse en el 
momento del nacimiento de los renacuajos. Así, la bolsa materna en las ranas marsupiales cumple una función coordinada.

\section{El control de la fisiología de la bolsa materna}

Eugenia del Pino concluyó que en las hembras de G. riobambae la bolsa materna tienen control de hormonas reproductivas. La formación de la bolsa puede ser gatillada por la hormona femenina estradiol-17 $\beta$, de acuerdo al trabajo de otros autores. Además, la administración intraperitoneal de progesterona produjo el cerramiento de la bolsa materna y la formación de cámaras embrionarias alrededor de esferas inertes que fueron insertadas en la bolsa materna. Estos experimentos revelaron que la progesterna - que es la hormona que regula la preñez de los mamíferos, o una hormona similar a esta-, controla la incubación de los embriones en la bolsa de la rana marsupial, y representa un caso de evolución paralela con los mamíferos respecto al control hormonal de la reproducción. Se han observado, además, folículos post ovulatorios grandes luego de la ovulación, estos se mantienen en el ovario durante el primer tercio de la incubación embrionaria; pero se desconoce si los folículos tienen una función similar al cuerpo lúteo de las hembras de mamíferos, cuya función es secretar la progesterona; si fuese así estaríamos frente a un hecho de evolución convergente.

Ovulación, maduración de los oocitos y preparación de la bolsa materna para la incubación de los embriones

Eugenia del Pino y sus colaboradores analizaron la posibilidad de inducir ovulación en la rana marsupial G. riobambae mediante la administración de la gonadotropina coriónica de origen humano y se determinó que ciertamente se puede inducir la maduración y liberación de óvulos mediante la administración de esta hormona, como en Xenopus laevis. La posibilidad de inducir la ovulación a voluntad de los investigadores mediante la administración de la gonadotropina coriónica es una de las características importantes de X. laevis y $G$. riobambae como modelos experimentales.

El cambio de oocito a huevo se debe al avance de la profase de meiosis I a la metafase de meiosis II, cambio que está gatillado por la progesterona en $X$. laevis y que se conoce como maduración de los oocitos. Las investigaciones siguientes permitieron determinar que de modo similar, la progesterona gatilla la maduración de los oocitos de G. riobambae. Además, la progesterona o una hormona similar interviene en la preparación y mantenimiento de las condiciones reproductivas de la bolsa marsupial: gatilla la maduración de los ovocitos, el cerramiento de la abertura de la bolsa marsupial y la formación de cámaras embrionarias vascularizadas para cada embrión en la bolsa materna. Con lo cual se concluye que la progesterona o una hormona similar tiene efecto tanto en la maduración de los ovocitos, como en los cambios en la bolsa materna asociados con la incubación de los embriones en rana marsupial G. riobambae. Lo cual pone en evidencia un paralelismo con los mamíferos en los procesos reproductivos, que se puede explicar en la necesidad de cumplir la función reproductiva fuera del agua.

\section{Relación entre los embriones y la bolsa materna}

Sus investigaciones han logrado demostrar que existe una relación estructural y fisiológica entre cada embrión y la bolsa materna en especies de la familia Hemiphractidae. En G. riobambae se forma 
un par de branquias acampanadas vascularizadas que recubren totalmente al embrión durante el desarrollo en la bolsa marsupial con lo cual se establece una comunicación íntima entre el embrión y la madre. Tanto las branquias acampanadas como las cámaras embrionarias de la bolsa materna tienen abundante vascularización y tienen microvellosidades que favorecen los intercambios materno - embrionarios; sin embargo la bolsa materna y las branquias acampanadas de los embriones se encuentran separadas por la presencia de la envoltura de fecundación y una delgada capa de gelatina que recubren a cada embrión.

Posiblemente la gelatina del huevo cumple una función en la asociación de los embriones con la bolsa materna; pero son las finas membranas de las branquias acampanadas las que favorecen la relación, puesto que la bolsa materna como las branquias acampanadas tienen vellosidades; a través de estas ocurre el intercambio de substancias durante los cuatro meses de incubación. Tales intercambios son posibles debido a los cambios integumentarios de la bolsa materna provocados por la hormona de la preñez - la progesterona o una similar -, pero además y en forma paralela por la presencia de las branquias acampanadas de los embriones y por la estrecha relación anatómica de las branquias acampanadas con la bolsa materna de la madre que representa una relación anatómica comparable a la placenta epitelio-corial de algunos mamíferos.

\section{Adaptaciones de la función excretora}

Siendo la excreción de nitrógeno uno de los requisitos de supervivencia de los animales, estos la eliminan como compuestos de amoníaco, urea o ácido úrico, por lo cual se les denomina amonotélicos, ureotélicos y uricotélicos, respectivamente. La excreción de amoníaco requiere abundante agua debido a su carácter venenoso, no así la eliminación de urea, que al no ser tóxica se elimina con menos agua. Los embriones de $G$. riobambae soportan un estado de estrés fisiológico de agua, por lo que su fisiología ha evolucionado para eliminar nitrógeno con mínima pérdida de líquido, que es posible con la excreción de urea. Se interpreta que el urotelismo de los embriones de $G$. riobambae es una adaptación al estrés de agua durante el período de incubación en la bolsa materna; es decir evolucionó hacia la excreción de urea, condición que además favorece la conservación de agua debido a que la urea acumulada en el fluido de la cápsula de cada embrión de la bolsa materna actúa como osmolítico ayudando a la acumulación de agua en la cápsula de cada embrión.

Este descubrimiento tuvo un importante efecto práctico en el laboratorio, luego de ensayos fallidos de medios de cultivo para embriones, se preparó un medio con urea para cultivar in vitro embriones de la rana marsupial $G$. riobambae. El cultivo in vitro de los embriones ha permitido estudiar las etapas del desarrollo embrionario temprano como la blástula, gástrula, néurula, etapas en las cuales se han encontrado características que se asemejan el desarrollo de las ranas marsupiales -anfibios anuros- con el desarrollo de los reptiles, las aves - los mamíferos, grupos de vertebrados que se hallan distantes desde el punto de vista filogenético.

\section{El ritmo del desarrollo embrionario temprano}

El desarrollo embrionario de la rana marsupial Gastrotheca riobambae en el interior de la bolsa materna ocurre a un ritmo sumamente lento. Por ejemplo, los embriones de la rana Xenopus laevis requieren 14 
horas desde la fecundación hasta culminar el proceso de gastrulación. En cambio en $G$. riobambae en mismo proceso requiere 14 días. El desarrollo embrionario lento solamente ocurre en los organismos que dan protección parental a sus embriones. Los mamíferos se desarrollan lentamente, y de modo similar, la protección que brinda la madre en la bolsa materna ha permitido que las ranas marsupiales tengan un ritmo de desarrollo embrionario lento.

\section{La gastrulación y el disco embriónico}

Los embriones de G. riobambae tienen un carácter netamente de anfibio - anuro con un clivaje total u holoblástico, con la formación del labio dorsal del blastoporo y la formación de un blastoporo alrededor de un amplio tapón de yema durante la gastrulación. Sin embargo se encontraron diferencias significativas, pues al concluir la gastrulación se reveló que las células que ingresaron por el blastoporo se acumularon alrededor del blastoporo formando un gran collar circumblastoporal. En la superficie del embrión se encontró un disco embriónico de células pequeñas alrededor del blastoporo cerrado. El cuerpo del embrión se desarrollará a partir de este disco embrionario como ocurre en las aves. El cuerpo del embrión del pollo se deriva de un pequeño disco superficial de células que se encuentran sobre la gran masa de yema que no está dividida en células, ya que el clivaje del huevo es parcial o meroblástico en las aves.
Se ha investigado el modo de gastrulación en ranas de las familias Terrarana: Eleutherodactylidae, Dendrobatidae, Centrolenidae y Leptodactylidae en comparación conXenopus laevis (Pipidae) y no se han encontrado especies que formen un disco embriónico como resultado de la gastrulación. Sin embargo, se encontró similitud entre el gran collar circumblastoporal de Gastrotheca riobambae con el prominente collar circumblastoporal de la gástrula de Epipedobates machalilla y de otras ranas dendrobátidas. Sin embargo, los dendrobátidos no forman un disco embriónico. Se concluyó que el disco embrionario de los embriones de G. riobambae representa un modo paralelo de evolución que ha permitido el desarrollo a partir de huevos grandes comparable al desarrollo de las aves.

\section{El retardo en el alargamiento del cuerpo de Gastrotheca riobambae}

Uno de los cambios fundamentales en el desarrollo embrionario es el paso de la forma esférica del huevo hacia la forma alargada de los renacuajos o del adulto de los vertebrados. El alargamiento del cuerpo se inicia en la gástrula media en Xenopus laevis por el proceso denominado de extensión convergente dorsal gatillado por la expresión del gen brachyury. De modo sorprendente E. del Pino y sus colaboradores han determinado que el alargamiento del cuerpo se inicia después de concluir la gastrulación en la rana marsupial G. riobambae, así como en la rana dendrobátida Epipedobates machalilla y en otras especies de la familia Dendrobatidae. Estos descubrimientos revelan que el aspecto fundamental de la gastrulación es el ingreso de células al interior del embrión por medio de los movimientos morfogenéticos que establecen el plan del cuerpo de los vertebrados con la formación de las capas germinales del ectodermo, mesodermo y endodermo. El alargamiento del cuerpo está disociado de la gastrulación en G. riobambae. El alargamiento del cuerpo puede o no estar acoplado a la gastrulación de acuerdo a la estrategia reproductiva de cada especie y a su velocidad del desarrollo embrionario. Así, especies como X. laevis, cuyos huevos

se desarrollan rápidamente en el agua tienen acoplados los procesos de 
gastrulación y alargamiento del cuerpo, pues su estrategia reproductiva requiere la rápida formación del renacuajo que es alargado. En cambio, la rana marsupial G. riobambae o las ranas dendróbatidas, que se desarrollan en nidos terrestres, no tienen la presión de alargar el cuerpo al mismo tiempo que realizan la gastrulación ya que los embriones tienen protección parental y se desarrollan lentamente. Es decir el acoplamiento de la gastrulación con el alargamiento del cuerpo está relacionado con la estrategia reproductiva y no con las relaciones filogenéticas de las especies de ranas.

\section{Tiempo, modo del desarrollo y el blastoporo}

Existe variación en el tiempo y modo de los procesos de desarrollo de los anfibios anuros: en unas especies es rápido y en otras especies es retardado. En ciertas familias el desarrollo es directo, es decir del huevo emerge una pequeña ranita, pero en otras ocurre metamorfosis sobre o dentro del cuerpo de los progenitores y en el medio ambiente. Según las circunstancias particulares de desarrollo embriónico han evolucionado diferentes estructuras y procesos que transcurren en tiempos diferentes. Esto explica el tamaño de los huevos: pequeños o grandes; la oogénesis multinucleada o mononucleada; la sincronía y asincronía de los eventos embriológicos: gastrulación, elongación del cuerpo, formación de la notocorda.

Las especies que están sujetas a presiones ambientales asociadas con el desarrollo acuático tienen huevos pequeños, procesos de desarrollo más rápidos y el cuerpo se alarga tempranamente porque ocurre solapamiento de la convergencia y extensión dorsales con la gastrulación, en tanto que especies que no tienen presiones asociadas al desarrollo acuático, porque tienen cuidado parental en bolsa marsupial como ocurre en Gastrotheca riobambae, o en los nidos terrestres de las ranas dendrobátidas, los huevos son grandes, no hay solapamiento del alargamiento del cuerpo con la gastrulación y los procesos de desarrollo embriónico son lentos, porque no hay "apuro" para que ocurran, por lo tanto se separan y no se aprecia simultaneidad en los eventos del desarrollo.

Recientemente la bióloga Alexandra Vargas analizó el tamaño de las células de la gástrula temprana en diez especies de ranas con huevos de 1,1 a 3,5 $\mathrm{mm}$ de diámetro. Encontró una relación directa entre el tamaño del huevo y el tamaño de las células de la gástrula temprana, tanto de las células vegetales como de las animales. En cambio, las células ecuatoriales, o de la zona marginal, fueron pequeñas en todas las especies independientemente del tamaño del huevo o modo de gastrulación. Las células marginales deben ingresar al interior de la gástrula para formar el cuerpo del embrión y por tal motivo deben ser pequeñas. Eugenia del Pino y Alexandra Vargas propusieron que las presiones evolutivas para mantener células pequeñas en la zona marginal han permitido que el blastoporo sea una característica universal de la gástrula de los anuros con huevos de diferentes tamaños y modos de gastrulación. La formación del blastoporo se ha mantenido durante la evolución de las ranas y ha facilitado la evolución de huevos grandes con grandes reservas de yema en las ranas con adaptaciones terrestres y la evolución del disco embrionario en el caso de la rana marsupial G. riobambae.

\section{Determinación de la asimetría izquierda - derecha}

En el cuerpo de los vertebrados existen órganos únicos, como el corazón que se encuentra localizado hacia la izquierda. La determinación de la asimetría izquierda - derecha de algunos órganos del cuerpo ocurre 
inmediatamente después de la gastrulación, en la néurula de todos los vertebrados, a excepción del pollo. El mecanismo de determinación de la asimetría izquierda - derecha ha sido ampliamente estudiado en la rana Xenopus laevis. El techo del intestino primitivo de la néurula de X. laevis presenta un área de forma aproximadamente triangular de mesodermo superficial con células mono-ciliadas, esta área es la placa de techo del gastrocele (GRP, por su siglas en inglés). El movimiento coordinado de los cilios del GRP en dirección de las agujas del reloj resulta en un flujo de fluido hacia el lado izquierdo y este movimiento gatilla la expresión de genes que determinan la posición asimétrica de los órganos, es decir, la asimetría izquierda - derecha de la posición de los órganos.

Era de interés determinar si existía el GRP ciliado en las néurulas de las ranas que retardan el alargamiento del cuerpo hasta después de la gastrulación. Los experimentos demostraron la presencia del GRP ciliado en cuatro especies de ranas, tres de ellas con solapamiento de la gastrulación y alargamiento del cuerpo: Xenopus laevis (Pipidae), Ceratophrys stoltzmanni (Ceratophrydae) y Engystomops randi (Leptodactylidae) y dos de ellas con separación entre los movimientos de la gastrulación y a largamiento del cuerpo, Epipedobates machalilla (Dendrobatidae) y Gastrotheca riobambae (Hemiphractidae). La presencia de cilios en el GRP en la néurula de ranas pertenecientes a cinco familias diferentes sugiere que el mecanismo utilizado para el establecimiento de la asimetría izquierda - derecha debe ser similar entre las ranas, a pesar de las diferencias encontradas en el inicio del alargamiento del cuerpo entre las diferentes ranas analizadas.

\section{Líneas recientes en la investigación}

En los últimos años las investigaciones de la biología del desarrollo se enmarcan en el ámbito de la genética molecular con el propósito de determinar la función específica de varios genes clave en la gastrulación, organización corporal, la modularidad. La estrategia seguida por E. del Pino ha sido la de determinar la presencia de proteínas de importancia en el desarrollo temprano mediante la inmuno-detección con anticuerpos específicos.

Así se logró identificar al mesodermo prospectivo y detectar diferencias en el inicio del alargamiento de la notocorda por la expresión de la proteína Brachyury lo que a su vez ayudó a caracterizar los modos de gastrulación. La expresión de la proteína LIMhomeobox1 (Lim1, conocida también como Lhxl) que está implicada en la formación de organizador Speman-Mangold en los embriones de X. laevis también se expresa en la rana marsupial Gastrotheca riobambae y en la rana dendrobátida Epipedobates machalilla. El análisis comparativo de Lim 1 permitió identificar retardo en la expresión del mesodermo del tronco (notocorda). Estos resultados están de acuerdo a los resultados obtenidos de la expresión de Brachyury.

Los genes vegt y mix 1 codifican para factores de transcripción que se expresan en el endodermo de Xenopus laevis y se consideran como marcadores del endodermo. Era de interés caracterizar molecularmente el endodermo de ranas con huevos de diferentes tamaños. El estudio comparativo indicó que las estrategias para la especificación del endodermo son conservadas en ranas tan diversas como la rana de desarrollo directo Eleutherodactylus coqui (Terrarana: Eleutherodatylidae), la rana marsupial Gastrotheca riobambae (Hemiphractidae), la rana con nidos terrestres Epipedobates machalilla (Dendrobatidae), las ranas con reproducción acuática y nidos de espuma Engystomops randi (Leptodactylidae) y la rana acuática Xenopus laevis (Pipidae). 
Es preciso destacar las contribuciones de jóvenes investigadores como el profesor investigador Óscar Pérez, que en colaboración con Richard Elinson de la Universidad de Duquesne, Pittsburg, Estados Unidos, estudió el gen vegt en Xenopus laevis; secuenció el gen vegt en Gastrotheca riobambae y Epipedobates machalilla y analizó su expresión en el desarrollo. Este gene es altamente conservado en la filogenia y se expresa tanto de las ranas como en el pez cebra y en el pollo. En esta línea avanza la investigación de la biología del desarrollo comparada de vertebrados que es el nuevo campo de la biología actual.

\section{CONCLUSIÓN}

En las ranas marsupiales la formación de la bolsa materna, el control fisiológico, la preparación de la bolsa para la incubación, la relación de esta con el embrión, así como la función excretora son respuestas a las demandas de modelos nuevos de desarrollo en la evolución de los anfibios anuros, y en su condición de vertebrados que se hallan en el umbral agua-tierra. Estas comprobaciones permiten concluir a Eugenia del Pino que "hay diferentes modos de hacer una rana".

El análisis epistemológico de las investigaciones de la biología del desarrollo que ha realizado Eugenia del Pino y sus colaboradores ecuatorianos y extranjeros durante cuatro décadas constituyen un excelente modelo de trabajo investigativo, pues combina el dominio de la base teórica y un depurado proceso metodológico mediante el cual llega a descubrir y explicar la biología del desarrollo de las ranas marsupiales y de otras especies de anfibios anuros.
El éxito alcanzado obedece a la continuidad en una línea de investigación, a la libertad de cátedra y el apoyo institucional de la PUCE, a la relación con investigadores de alto nivel científico de otros países; con todo ello plasmó en un trabajo científico trascendente en las ciencias biológicas, a la vez que logró construir un eje orientador de las investigaciones de la biología del desarrollo de vertebrados, tan importante en los tiempos actuales que demandan mayor atención a los fenómenos ontogenéticos, porque estos imponen limitaciones y direccionamientos a los fenómenos evolutivos; estos aspectos están siendo abordados por la biología evolutiva en la presente década.

Al finalizar este apasionante discernimiento cabe recordar la expresión del filósofo de la ciencia Dampier: "La ciencia es el conocimiento ordenado de los fenómenos naturales y de las relaciones que existen entre ellos". La buena ciencia busca explicar los hechos, no solo describirlos. Esto se refleja en las investigaciones de la biología del desarrollo de los anfibios anuros que se ofrece en este análisis.

\section{AGRADECIMIENTOS}

El presente ensayo sobre las investigaciones en las ranas marsupiales y otras especies de anuros se realizó sobre la base de los trabajos publicados por Eugenia del Pino, que conservo en mi biblioteca y otros que me facilitara la autora; fue complementado por Eugenia en lo referente a los avances más recientes de embriogénesis temprana que se sustenta en la biología molecular y genética del desarrollo, por lo cual cumplo con expresarle mi agradecimiento. 


\section{REFERENCIAS BIBLIOGRÁFICAS}

del Pino EM. 1989. Marsupial Frogs. Scientific American 260:1 10-118.

del Pino EM. 2013. Biología y desarrollo embrionario de las ranas marsupiales (Hemiphractidae). Revista Nacional de Cultura Letras Artes y Ciencias del Ecuador 22:41-68.

del Pino EM, Venegas-Ferrín M, Romero-Carvajal A, Montenegro-Larrea P, Sáenz-Ponce N, Moya IM, Alarcón I, Sudou N, Yamamoto S, Taira M. 2007. A comparative analysis of frog early development. Proceedings of the National Academy of Sciences of the United States of America 104:1 1882-1 1888.

Elinson RP, del Pino EM. 2012. Developmental diversity of amphibians. WIREs Developmental Biology 1:345-369.

Sáenz-Ponce N, Santillana Ortiz JD, del Pino EM. 2012. The gastrocoel roof plate in embryos of different frogs. Differentiation 83:S62S66.

Sudou N, Garcés-Vásconez A, López-Latorre MA, Taira M, del Pino EM. 2016. Transcription factors Mix 1 and VegT, relocalization of vegt mRNA, and conserved endoderm and dorsal specification in frogs. Proceedings of the National Academy of Sciences of the United States of America 1 13:5628-5633.
Vargas A, del Pino EM. 2017. Analysis of cell size in the gastrula of ten frog species reveals a correlation of egg with cell sizes, and a conserved pattern of small cells in the marginal zone. Journal of Experimental Zoology Part B: Molecular and Developmental Evolution 328B:88-96.

\section{EUGENIA DEL PINO:}

Realizó estudios de Biología en la PUCE, Quito, Vassar Collegue, Poughkeepsis, New York y Emory University, Atlanta, Georgia, donde obtuvo el Doctorado (Ph D). Por sus investigaciones del desarrollo de anfíbios anuros alcanzó distinciones y premios como: Miembro de la Academia de Ciencias de América Latina, Premio L'Oreal UNESCO para la Mujer en Ciencia, Medalla TWAS en Biología de la Academia de Ciencias del

Mundo en Desarrollo, Miembro Honorario Extranjero de la Academia Americana de Artes y Ciencias de Estados Unidos y Miembro Asociado Extrajero de la Academia Nacional de Ciencias de Estados Unidos, Premio Eugenio Espejo en Ciencias, 2012. Desempeñó funciones en CONACYT y CONUEP, Vicepresidente para Ecuador de la Fundación Charles Darwin para las Islas Galápagos.

\section{OSWALDO BÁEZ:}

Doctor en Biología, Universidad

Central del Ecuador. Fue profesor principal de la Escuela de Biología y de la Carrera de Ciencias Biológicas y Ambientales, Universidad Central y de la Facultad de Ciencias Exactas y Naturales, Universidad Católica de Quito. Coordinador de Proyectos de Conservación de la Naturaleza en la Fundación Natura. Asesor del Ministerio del Medio Ambiente, 2003. Presidente de la Sociedad Ecuatoriana

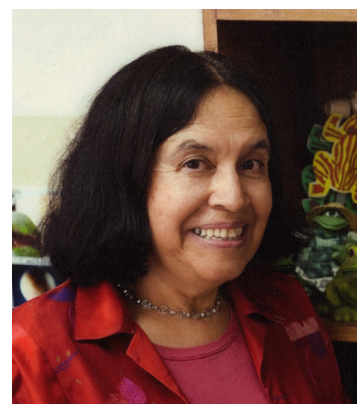

de Biología. Invitado por la Academia de Ciencias de Filadelfia y Museo Smithsoniano de Historia Natural, Washington. Ha participado en Jornadas de Biología, congresos y cursos como expositor y conferenciante. Es autor y coautor de varios libros, escritor de artículos y ensayos biológicos y sociales, trabaja en temas de biología teórica y de divulgación. 